\title{
UNA APROXIMACIÓN A LA CAPILLA DE MÚSICA DE LA CATEDRAL DE TORTOSA (TARRAGONA): 1700-17501
}

\author{
Marian Rosa Montagut
}

\section{Resumen}

El presente artículo pretende ofrecer una aproximación documentada a la capilla de música de la catedral de Tortosa, un centro de particular relevancia por cuanto dicha ciudad resultó ser, en otros tiempos -por su antigüedad, historia y situación geográfica privilegiada-, una de las más ilustres de la Península y con la cual tuvo una especial vinculación Miguel Querol. De este modo, aunque la Tortosa de principios del siglo XVIII había perdido ya parte del empuje de épocas anteriores, su diócesis seguía abarcando territorios de las actuales provincias de Tarragona, Teruel, Castellón y Valencia, y la capilla musical de la seo, a pesar de no ser por entonces especialmente numerosa y brillante para ser catedralicia, parece que fue un lugar de atracción no sólo para los músicos catalanes sino asimismo de otros lugares cercanos como Aragón y/o Valencia.

\begin{abstract}
The present paper tries to offer a documented approach to the musical chapel of Tortosa cathedral, a particularly important centre of musical activity, based on the long history and exceptionally good geographical situation of the town, which represented, in other times, one of the most illustrious cities of the Iberian peninsula. Miguel Querol had a close relation with Tortosa, as well. Therefore, and even considering that Tortosa lost a part of its previous pre-eminence at the beginning of the $18^{\text {th }}$ century, Tortosa's diocese continued covering wide territories (nowadays belonging to the provinces of Tarragona, Teruel, Castellón and Valencia). The capilla musical of the cathedral, may be not very large in its number of musicians for the period, perhaps not very brilliant for the expected importance of a cathedral's musical chapel, was, paradoxically, an attractive place for musicians, not only from Catalonia, but also coming from the ancient kingdoms of Valencia and Aragon.
\end{abstract}

Con ocasión de presentar un estudio para la presente miscelánea en homenaje al Dr. Miguel Querol, no quisiera dejar pasar la ocasión de aportar, siquiera sea brevemente, unas líneas a propósito de su gran vinculación con la ciudad de Tortosa, cuya capilla musical catedralicia es el objeto de este trabajo.

La proximidad geográfica entre Tortosa y la localidad natal de Miguel Querol (Ulldecona) fue, muy probablemente, la causa de que éste tuviese, ya desde su infancia, diversos contactos con dicha

1. Estudio realizado con el soporte del Departament d'Universitats, Recerca i Societat de la Informació de la Generalitat de Catalunya i del Fons Social Europeu. Este trabajo se enmarca en el Proyecto de Investigación El fondo antiguo de música de la catedral de Barcelona conservado en la "Biblioteca de Catalunya". Estudio de las fuentes y recuperación patrimonial. 2: El repertorio en lenguas romances (HUM 2005-08394-C02-02), 2005-2008, del que es Investigador Principal el Dr. Antonio Ezquerro Esteban (Departamento de Musicología, Institución "Milá y Fontanals”, CSIC, Barcelona). 
ciudad, algunos de los cuales, a posteriori, repercutirían directamente en sus intereses y preparación musicológica. Por poner un ejemplo: Miguel Querol se trasladó de Ulldecona a Tortosa a los doce años (en 1924) para ingresar en el colegio (seminario) de San José y, permaneciendo allí durante dos cursos escolares (hasta que ingresó, en 1926, en el Monasterio de Montserrat), durante los mismos parece que recibió una completísima formación tanto musical ${ }^{2}$ como, al menos, de latín, retórica y poética ${ }^{3}$. Asimismo, Querol realizó varios trabajos musicológicos y/o musicales relacionados con dicho lugar o sus ciudadanos, como así lo muestran, entre otros, sus artículos sobre Felipe Pedrell (a quien incluso llamó "padre de la Musicología española") ${ }^{4}$ o sus armonizaciones de melodías populares tortosinas 5 .

$* * *$

\section{La Catedral de Tortosa: Capilla musical (1700-1750)}

La estructura y funcionamiento de la capilla musical de la seo de Tortosa no difería sustancialmente, en la primera mitad del setecientos, de la mayoría de capillas hispánicas del momento: estaba formada por un maestro de capilla -llamado también en la documentación "maestro de canto"-, un organista, varios cantores, niños de coro $^{6}$ y tañedores de distintos instrumentos (chirimía, bajón, violín, ...).

Sin embargo, al menos en las primeras décadas de la centuria, esta capilla de música no resultó ser especialmente numerosa y brillante para ser catedralicia, lo que sucedió, muy probablemente, debido a la crítica situación que vivió la ciudad durante esos años ${ }^{7}$. Los documentos recogen, al respecto,

2. El director del colegio seminario de San José era, por entonces, el sacerdote y músico José María Peris. Este compositor dio, durante dichos años, un gran impulso al estudio de la música entre los seminaristas consiguiendo, entre otras cosas, que dicha disciplina adquiriese el rango de asignatura obligatoria. [Véase: RuBio ToRREnT, Maria Cinta: Homenatge a l'Excm. Sr. en Miquel Querol i Gavaldà (1912) en el seu 75 aniversari. Ulldecona, Ajuntament d'Ulldecona, 1987].

3. El propio Querol afirma en la "Introducción" de su libro Poesies, que sus dotes de versificación y de realizar combinaciones métricas los adquirió a los trece años, cuando estudiaba en Tortosa: "Entre les assignatures corresponents al tercer any de carrera eclesiàstica, teníem una assignatura titulada Retòrica i Poètica essent el seu professor un sacerdot que es deia mossèn Pedret. Allí vaig aprendre què era un rodolí, un tercet, una quarteta, una octava real, un sonet, un madrigal [...]. Però el més important del cas era que ens demanà que a la classe següent li portéssim tota aquesta llista de combinacions mètriques amb poesies fetes per nosaltres mateixos". Véase: Querol, Miquel: Poesies. Tarragona, Autoritat portuària de Tarragona, 1998, p. 17.

4. Miguel Querol realizó, entre otros trabajos, la entrada "Felipe Pedrell" del diccionario enciclopédico Die Musik in Geschichte und Gegenwart [Kassel-Basilea, Bärenreiter, 1962, vol.10, cols.989-991], así como los artículos "Felipe Pedrell, compositor. El Comte Arnau" [en Anuario Musical, 27 (1972), pp. 21-38] y "Felipe Pedrell, padre de la Musicología Española (en el centenario de su muerte)" [en Ritmo, septiembre de 1972, p. 4] donde afirma que "todos los caminos y direcciones de la investigación musical en España fueron iniciados por Pedrell" y que éste "con sus búsquedas y orientaciones como musicólogo formó e inició en la investigación musical a otro gigante de la Musicología, Monseñor Higinio Anglés, fundador del Instituto Español de Musicología del CSIC".

5. Como, por ejemplo, la armonización a 5 voces de la melodía popular "La fonteta del moro" [Barcelona, Clivis, 1963], o las armonizaciones a 4 voces de las canciones de navidad "Sant Josep va a buscar foc" y "N'ha berenat lo Jesuset" [QUEROL, Miguel: Noves Cançons de Nadal. Populars catalanes $i$ valencianes. Barcelona, Clivis, 1972].

6. Aunque a falta de un estudio más pormenorizado de la documentación catedralicia no se han encontrado datos concretos sobre el número, edades y tareas de los niños de coro o infantillos, queda corroborado que, al igual que en las demás catedrales hispánicas del momento, los niños tiples formaban parte de la capilla musical dado que, por un lado, la documentación recoge, entre las obligaciones del maestro de capilla, la de "educar, enseñar y adestrar als miñons de tiples en lo cant y música ab lo demes que se requerex en ells" [E: TO, Actas Capitulares, 10.03.1708] y, por otro, en las hojas de guarda de algunos libros de coro de la época aparecen anotaciones manuscritas a tinta con sus nombres, dibujos, caricaturas, etc.

7. Por una parte, Tortosa vivió una situación realmente crítica en la segunda mitad del siglo XVII, como consecuencia de la Guerra "dels Segadors" (1640), la terrible peste bubónica de 1650 (que afectó a una sexta parte de la población), y las posterio- 
comentarios como los siguientes:

1707 "[...] [se deniega un Beneficio] en vista de les males cobrances y contratemps en esta guerra [de Sucesión] [...]"8.

1708 "[...] hallandose la capilla de ella [la catedral de Tortosa] tan decaida [...]"9. "[...] Deliberarunt que per ara al comensal Fran.co Aragones a $\mathrm{M}^{\mathrm{o}}$ Antoni Boix, y a $\mathrm{M}^{\mathrm{o}}$ Geroni Vermell pbres per remuneracio de son treball en entonar, y asistir al facistol, y servey gran fan en ell en esta ocurrencia de temps que son pochs los ressidents $[\ldots]]^{\prime 10}$.

Pese a ello, afirmaba Vicente Ripollés que Tortosa era, en aquella época, "el centro donde acudían los cantores y buenas voces del Maestrazgo"11 y, de ser cierto dicho comentario (como suponemos), todo parece apuntar que, a pesar de la "crisis" del momento, muy probablemente la seo tortosina debió ser asimismo un lugar de atracción para los músicos (no sólo cantores sino también para quienes pretendían ejercer como maestros de capilla, organistas o instrumentistas) de otros lugares cercanos, dado que, como se verá a continuación, la mayor parte de los componentes de su capilla musical de que se tiene conocimiento eran naturales, no generalmente de Cataluña, sino más bien de Aragón y/o Valencia.

En cuanto a los miembros de la capilla musical, afirma Enric Bayerri que, en 1704, el Cabildo de la catedral de Tortosa tenía cuatro comensalías aplicadas a la misma ${ }^{12} \mathrm{y}$, según Josep M. Gregori, en los últimos años del siglo XVII y primeros del XVIII, además del maestro (Baltasar Sanz) y el organista (Tomás Serrano), el núcleo de la capilla lo integraban cuatro cantores ${ }^{13}$. Sea como fuere, la mayor parte de las obras compuestas para ser interpretadas en la seo tortosina durante la primera mitad del siglo XVIII que se conservan, están escritas para cuatro u ocho voces con acompañamiento, a la vez que los villancicos, además, suelen tener partes instrumentales (lo más común a partir de la segunda década de la centuria, además del acompañamiento, será la presencia de dos violines y bajo para los violines) de manera que, es de suponer que la citada capilla -bien en "plantilla", bien como "contratación" de un servicio concreto- contase como mínimo con los cantores e instrumentistas que hacían posible la interpretación de las obras compuestas para cada ocasión. Asimismo conviene señalar que, según algunas informaciones documentales secundarias al respecto, parece que esta capilla se fue res-

res malas cosechas, falta de comercio, hambre, etc. y, por otro lado, ya en 1701 empezarían a sentirse en la zona las tensiones de la inminente Guerra de Sucesión que retrasarían la recuperación demográfica y económica de la ciudad durante varios años. Véase: BAYERRI, Enric: Historia de Tortosa y su comarca. Vol. 8. Tortosa, Imprenta de Algueró y Baiges, 1957; O'CALLAGHAN, Ramón: Anales de Tortosa (I). Tortosa, Centre de Lectura de les Terres de l'Ebre, 1995 [Reproducción del facsímil de 1886]; FERNÁNDEZ y Domingo, Daniel: Anales o historia de Tortosa. Tortosa, Biblioteca Ebrenca, 1997.

8. Documento publicado por: BonASTRE, Francesc: "Nota biogràfica: Baltasar Sanz”, en Recerca Musicològica, VIII (1988), pp. 137-141; para la cita concreta, véase p. 141.

9. Carta del 10 de marzo de 1708, encuadernada con las Actas Capitulares [E: TO] de la misma fecha.

10. E: TO, Actas Capitulares, 18.09.1708. Dicho texto nos aporta explícitamente la información de que, en ese momento, había "pocos residentes" en la capilla de música, a la vez que parece indicar implícitamente (en el comentario "en esta ocurrencia de tiempo"), que esa situación se debía a unas circunstancias particulares y concretas que, muy probablemente, eran las consecuentes de los conflictos que trajo consigo la Guerra de Sucesión (una "purga" política para las iglesias de la Cataluña pro austriacista...). La particular situación económica del momento sería la causante de que, en ocasiones, se recurriese a solicitar los servicios de cantores o instrumentistas "externos", a los que se remuneraba.

11. RIPOllés PÉREZ, Vicente: Músicos castellonenses. Castellón, Sociedad Castellonense de Cultura, 1936, p. 162.

12. BAYERRI, Enric: Historia de Tortosa y su comarca. Tomo 8. Tortosa, Imprenta de Algueró y Baiges, 1957, p. 732.

13. GREGORI I CifRÉ, Josep Ma.: "Joan Crisòstom Ripollès (1678-1746) a les oposicions del magisteri de capella de la seu 
tableciendo con el transcurrir del siglo y la superación de la crisis de las primeras décadas. Maestros de capilla

En la seo tortosina, el cargo de maestro de capilla iba unido a una comensalía, la de San Miguel ${ }^{14}$, y las obligaciones o funciones que debía desempeñar dicho maestro eran, al menos, las siguientes: enseñar canto llano a los obispos y a tres de sus pages de forma gratuita, así como a todos los canónigos y a un page de cada uno de ellos, y a los miembros de la mensa que quisieran aprenderlo; educar, enseñar y adiestrar a los niños de coro en el canto y la música; cumplir todo lo demás que en esta y las demás catedrales acostumbran y tienen obligación maestros similares, como es componer todas las músicas que sea menester las cuales, tras la muerte del maestro o pasando éste a otro lugar, tendrán que quedar en dominio de su iglesia ${ }^{15}$.

Baltasar Sanz (1673-1708c) ${ }^{16}$. La capilla de música de la seo tortosina estaba regida, a comienzos de siglo, por Baltasar Sanz (*Brea -Zaragoza-, 1654c; †Tortosa -Tarragona-, 1708c), según las numerosas referencias al desempeño de dicho cargo por el mismo en las actas capitulares, desde el año 1673. Al parecer, Baltasar Sanz rigió el magisterio de esta catedral desde el 16 de junio de dicho año hasta su muerte (acaecida muy a principios de 1708) dado que, según la documentación consultada, en 1708 el cargo de Maestro de Capilla queda vacante por la muerte del maestro Baltasar Sanz “que ocupó dicho cargo de forma ejemplar desde 1673"17. Sin embargo, pese a que Sanz rigió durante casi 36 años el magisterio tortosino, en el archivo de dicha seo no se conserva la música de ninguna de sus composiciones, si bien se anota el texto de tres de sus villancicos en un impreso de 1701 conservado en el mismo ${ }^{18}$ que describe la celebración de unos festejos tortosinos en los que se cantaron varios de sus villancicos: "después de la Epistola cantò la Capilla un Villancico hecho al caso, las vozes dulces, sonoras las consonancias, la composicion de el Licenciado Baltazar Sans Racionero, y Maestro de Capilla bastantemente conocido por sus obras, y su ingenio, y es lo mas tener tan buen juizio, quien es gran

de Tortosa del 1708", en Butlletí arqueològic, V/14 (1992), pp. 137-147; ID.: “Tortosa”, en Diccionario de la Música Española e Hispanoamericana. Vol. 10. Madrid, SGAE, 2002, pp. 424-425.

14. "Y attenent axi matex a que la comensalia anexa al dit magisteri es presbyteral a sua fundatione" [E: TO, Actas Capitulares, 09.03.1708]. "M.e. de capella de la pnt Iglesia ab provisio de la comensalia a dit magisteri anexa" [Ibid., 10.03.1708].

15. Las Actas Capitulares [E: TO] de 10.03.1708 recogen estas obligaciones con motivo del nombramiento del nuevo maestro (Josep Escorihuela) que, suponemos, serían las mismas que tenía el anterior (Baltasar Sanz).

16. Las fechas aquí anotadas, tanto en éste como en los demás casos similares del presente estudio [al inicio del párrafo, junto al nombre en negritas del músico en cuestión], hacen referencia a los años en que éste ocupó su cargo en la capilla musical catedralicia de Tortosa.

17. E: TO, Actas Capitulares, 10.01.1708. Al parecer, durante sus últimos años de magisterio, Baltasar Sanz contó con la ayuda de Joan Garcia, músico que posteriormente se ofreció para regir la capilla provisionalmente durante unos meses (los que transcurrieron entre la muerte de su maestro y las oposiciones por concurso a la plaza). Finalmente, sin embargo y aunque opositó tras ello a dicho puesto, no acabaría desempeñando allí el magisterio sino el cargo de Tenor, al que optó asimismo por oposición, como luego se verá. [Véase, al respecto, la carta que el organista Tomás Lucas Serrano dirige al Cabildo de la catedral tortosina, encuadernada en E: TO, junto con las Actas Capitulares, de 18.09.1708].

18. Se trata de Alborozos festivos, leales obsequiosas demostraciones con que la fidelissima y exemplar ciudad de Tortosa, celebró el feliz arribo a su real corte de nuestro gran monarca y señor D. Felipe de Borbon rey de las españas (que Dios le guarde), Barcelona, Rafael Figueró, 1701. Este impreso anónimo se conserva en la barcelonesa Biblioteca de Cataluña (signatura 9645 R.85501), así como en el propio archivo de la Catedral de Tortosa (ejemplar sin catalogar).

19. Alborozos festivos, leales obsequiosas demostraciones..., op. cit., p. 10. No obstante lo referido sobre este músico ("bastante conocido por sus obras, y su ingenio"), de todos los diccionarios biográficos de música consultados, incluidos los enciclopé- 
Poeta, y gran Musico"19.

Baltasar Sanz ha sido un músico, hasta la fecha, poco estudiado y del que apenas existen algunas noticias dispersas ${ }^{20}$. Al parecer, este músico natural de la localidad zaragozana de Brea, se formó como "infantico" en la escolanía de El Pilar de Zaragoza antes de ocupar el magisterio catedralicio tortosino, y se conservan algunos villancicos de este "gran poeta y gran músico" 21 -con texto y música-, al menos, en el archivo de la iglesia de San Pedro de Canet de Mar (lugar que de momento no ha sido relacionado directamente con este maestro) y en la barcelonesa Biblioteca de Cataluña.

Josep Escorihuela (1708-1743). A partir de marzo de 1708, sería Josep Escorihuela (*Morella -Castellón-, 1674; †Tortosa -Tarragona-, 1743) el encargado de regir el magisterio catedralicio tortosino. Este músico -sobrino del maestro igualmente apellidado Isidro- ocupó, previamente, el cargo de maestro de capilla en la catedral metropolitana de Tarragona (muy probablemente, desde el 1 de enero de 1695) y, en 1708, ocupando todavía el citado cargo tarraconense, formó parte del jurado para la oposición al magisterio catedralicio de Tortosa siendo finalmente él mismo, quien acabaría quedándose con el puesto 22 (que desempeñó desde su nombramiento, el 10 de marzo de 1708, hasta poco antes del final de sus días, en agosto de 1743). En cuanto a su producción musical, conviene destacar la gran cantidad de villancicos que compuso durante sus aproximadamente 35 años de magisterio, muchos de los cuales se conservan actualmente en el archivo catedralicio tortosino 23 .

Valero Moreno y Polo (1743-1780c). Al producirse de nuevo la vacante del magisterio a finales de agosto de 1743, como consecuencia del deceso de Josep Escorihuela, se pensó en el hermano de Juan Moreno y Polo (quien, por entonces, desempeñaba la organistía) para ocupar dicho puesto. El cabildo de la seo de Tortosa se informó de las cualidades musicales de Valero Moreno y Polo (*La Hoz de la Vieja -Teruel-, 1714; †Tortosa -Tarragona-, 1780c) y, tras recibir unas cartas con referencias (de los,

dicos, su entrada sólo aparece en el Diccionario de la Música Labor de Joaquín PENA e Higinio AngLÉs (Barcelona, Labor, 1954, vol. II, p. 1965), donde lo único que se anota sobre el mismo es que se trata de un "compositor español desconocido del siglo XVII". [Véase al respecto: Rosa Montagut, Marian: "Música y fiesta barroca: celebraciones en Tortosa en honor a Felipe V (1701)", en Anuario Musical, 59 (2004), pp. 85-114].

20. Véase: GonzÁlez Valle, José V. et al.: "Regesta de noticias referentes a la música en las actas capitulares del Pilar (1656-1676)", en Aragonia Sacra, I (1986), pp. 187-195; BonASTRE, Francesc: "Nota biogràfica: Baltasar Sanz", en Recerca Musicològica, VIII (1988), pp. 139-141; Rosa MonTAGUT, Marian: "Música y fiesta barroca: celebraciones en Tortosa...", op. cit.

21. Resulta interesante, sin embargo, esta información implícita de que era el mismo Baltasar Sanz quien, en general, podía haber escrito tanto la parte musical como la literaria de sus composiciones.

22. Sobre el proceso de dichas polémicas oposiciones, puede verse: GREGORI I CIFRÉ, Josep Ma.: "Joan Crisòstom Ripollès (1678-1746) a les oposicions del magisteri de capella de la seu de Tortosa del 1708”, en Butlletí arqueològic, V/14 (1992), pp. 137147; y, Rosa Montagut, M. Amparo: "Josep Escorihuela: maestro de capilla de la catedral de Tortosa (1708-1743). 1. Biografía crítica”, en La composición musical en lengua vernácula en el ámbito eclesiástico hispánico (primera mitad del siglo XVIII): villancicos a la Virgen de la Cinta de Josep Escorihuela en la catedral de Tortosa. Trabajo de Investigación, Universitat Autònoma de Barcelona, 2005, pp. 109-134.

23. Sobre este músico pueden verse, entre otros, los siguientes trabajos: Pedrell i SABATÉ, Felip: "Documentos inéditos para su Diccionario", en $E$ : Bbc, M.942, Caja 2 ("Escorihuela, Jose"); GREGORI, Josep Ma.: "La música a la Catedral de Tortosa a principis del segle XVIII: el memorial de l'organista Tomàs Serrano", en Recerca Musicològica, XIII (1998), pp. 63-76; BonASTRE I BERTRAn, Francesc: "Escorihuela. 2. Escorihuela, Josep", en Diccionario de la Música Española e Hispanoamericana. Vol. 4. Madrid, SGAE, 1999, p. 732. Asimismo, puede consultarse una desarrollada biografía crítica sobre el mismo así como un estudio e inventario de su producción musical en: Rosa MonTAGuT, M. Amparo: "Josep Escorihuela: maestro de capilla de la catedral de Tortosa (1708-1743). 1. Biografía crítica. 2. Producción musical”, en La composición musical en lengua vernácula..., op. cit., pp. 109-157. 
por entonces, maestro de capilla de La Seo de Zaragoza -José Lanuza- y organista de El Pilar -Tomás Soriano-, pues los hermanos Moreno y Polo -José, Juan y Valero- se habían formado musicalmente como niños cantores en las catedrales zaragozanas) y algunas de sus composiciones musicales, fue elegido para el cargo, sin oposición, el 10 de septiembre del mismo año. Valero tomó posesión del magisterio el 8 de octubre de 1743 y ocupó dicho puesto hasta su muerte, acaecida en Tortosa, cerca de 1780. En el archivo catedralicio tortosino se conservan composiciones en las que consta solamente el apellido "Moreno", lo que dificulta saber con certeza cuáles son del propio Valero y cuáles de su hermano Juan, dado que ambos coincidieron durante varios años en la capilla musical de dicha seo donde escribieron obras musicales, aunque el primero lo hizo como maestro de coro y el segundo como organista ${ }^{24}$.

\section{Organistas}

Tomás Lucas Serrano (1669-1710c). La organistía tortosina fue desempeñada por el comensal Tomás Lucas Serrano (?, 1649; †Tortosa -Tarragona-, 1710c) ${ }^{25}$ desde 1669. Al parecer, este organista tuvo que aprender además a tañer el arpa, a petición del maestro Baltasar Sanz, tras pasar éste a regir la capilla en 1673:

[Carta de Baltasar Sanz al Cabildo, 1707:] “[...] a falta de no haver alguien que tuviesse la havilidad de Arpista, como la hay en las más Iglesias, [...] procure rogar al Com[ensa]l Thomas Serrano, M.tro y Organista de esta Santa Iglesia, para que aplicandose a tañer este Instrumento resarciese falta tan notable, lo que hizo gustosso, y sin tener obligacion, aplicose al acomp[añamien]to y de esta forma a proseguido treinta y quatro años, asta que la desgracia de huna cayda le ha tenido seis messes en casa [...]"26

De este modo el organista Tomás Lucas Serrano aprendió asimismo a tocar el arpa y se ocupó de suplir la falta de arpista (cargo, curiosamente, no presente en la capilla musical de esta catedral), desde 1673 hasta mediados de 1706 aproximadamente, año en que, al parecer, tras sufrir éste una caída que le tuvo seis meses en casa (durante los cuales, por lo tanto, no cumpliría con sus funciones en la capilla), dejó de tocar el arpa ocupándose, a partir de ese momento, únicamente de su cargo que era propiamente el de organista.

En 1708 (a los 59 años), tras haber desempeñado la organistía catedralicia tortosina durante 39 años, Tomás Lucas Serrano solicitó al cabildo que se aceptase a su sobrino, Ildefonso Serrano, para ayudarle en sus funciones y, posteriormente, concederle la sucesión de la comensalía del órgano sin

24. Sobre Valero Moreno y Polo, véase: PRECIADO, Dionisio: Doce compositores aragoneses de tecla (siglo XVIII). Madrid, Editora Nacional, 1983, pp. 45-55; ID.: "Moreno y Polo. 3. Valero", en Diccionario de música española e hispanoamericana. Vol. 7. Madrid, sGae, 2000, p. 810; Gembero Ustárroz, María: “Moreno Polo. (3) Valero Moreno Polo", en The New Grove Dictionary of Music and Musicians. Vol. 17. New York, Oxford University Press, 2001, p. 112; EzQuerro Esteban, Antonio: "Nuevos datos para el estudio de los músicos Nebra en Aragón”, en Anuario Musical, 57 (2002), pp. 113-156.

25. Sobre este músico puede verse: GREGORI I CIFRÉ, Josep Ma.: "Joan Crisòstom Ripollès (1678-1746) a les oposicions del magisteri de capella de la seu de Tortosa del 1708", en Butlletí arqueològic, V/14 (1992), pp. 137-147; ID.: "La música a la Catedral de Tortosa a principi del segle XVIII: el memorial de l'organista Tomàs Serrano", en Recerca Musicològica, XIII (1998), pp. 63-76; ID.: "Serrano, Tomás", en Diccionario de la Música Española e Hispanoamericana. Vol. 9. Madrid, SGAE, 2002, p. 954.

26. Documento publicado por: BonASTRE, Francesc: "Nota biogràfica: Baltasar Sanz", en Recerca Musicològica, VIII (1988), pp. 139-141; cita concreta en p. 141. 
concurso de oposición. Dicha solicitud queda recogida en el siguiente escrito:

"El comensal Thomas Serrano maestro de organo desta S.ta Igl.a [...]. Dize, mui Iltr.e S.r que por hallarse con dicha hedad, o, por defecto natural siente años ha y se le va aumentando de cada uno tal flaqueza en las manos y en el pulso maxime en refrescando el tiempo que se le ponen medio baldadas sin tener valor en los dedos para poder executar lo que la inventiva dictar y el arte requiere, pues a pocos compases que tañe y mas si es glosa se le rinden las manos [...] lo qual es mui facil de notar de quien oir tañer, $[\ldots]$ deseando que por dichos impedimentos no quede fraudado el Culto Divino y el suplicante no tenga la pena de no poder dar el devido cumplim[ien]to a su oblig[acio]n. Por tanto suplica a V.S. Ilt.ma quan humilm[en]te puede [...] que pues dicho suplicante se halla con dichos impedimentos y con un sobrino organista llamado Ildefonso Serrano [...] el qual parece al suplicante y a algunos que les favorecen que se dispone medianamente en tañer el organo [...] Y siendo aun como es mui mozo y parece tiene genio para organista [...] quiere dicho suplicante que buelva a Caragoza y vaia a otras partes donde florezca la musica para que tome los aires de unos y otros para conseguir lo que no se puede por arte solamente adquirir $[\ldots]]^{\prime 27}$

Ildefonso Serrano (1708-1731) ocuparía al parecer, tras dicha petición, el cargo de "organista suplente" de la catedral hasta que, en 1731, se realizarían unas oposiciones al puesto (en las que el propio Ildefonso formaría parte del tribunal examinador), en las cuales compitieron por la plaza Juan Moreno y Polo, y Juan Mir y Llusà 28 .

Juan Moreno y Polo (1731-1776), por su parte, sería quien obtendría el cargo en dicho concurso $^{29}$. Este músico (además de organista, compositor) rigió la organistía de la catedral de Tortosa durante 45 años (desde agosto de 1731 hasta su deceso), coincidiendo primero con el maestro de capilla Josep Escorihuela y, unos años más tarde, con su propio hermano Valero Moreno y Polo en el mismo puesto $^{30}$.

27. Carta encuadernada en E: TO, junto con las Actas Capitulares, de 18.09.1708. La respuesta, recogida en las Actas Capitulares de la misma fecha, fue la siguiente: “[...] attesa la Suplica, en escrits del Comensal Thomas Serrano M.e de Orgue [...] Deliberarunt se consulte dita suplica ab lo P. M.e Bosch y ab vocals, y son sentir se reposte per a poderse deliberar y fer lo que sia arbitrable en alivio y consuelo del dit M.e de Orgue".

28. "Compusieron el tribunal junto a Escorihuela, el organista suplente de la catedral, presbítero Ildefonso Serrano, así como el maestro de capilla y organista de Morella, mosén Félix Vicente. Compitió por la plaza, junto a Moreno y Polo, el clérigo natural de la villa de Borges, de Urgell, Juan Mir y Llusà, entonces maestro de capilla de la Seu de Manresa", [E: TO, Actas capitulares, 28.07.1731]. Sobre el citado maestro de Manresa (entre 1726 y 1731), natural de Lérida, véase: VILAR, Josep Ma.: La música a la seu de Manresa en el segle XVIII. Manresa, Centre d'Estudis del Bages, 1990; ID.: "Mir, Joan", en Diccionario de la Música Española e Hispanoamericana. Vol. 7. Madrid, SGAE, 2000, p. 599; BALlús CAsóliva, Glòria: La Música a la Col-legiata Basílica de Santa Maria de la Seu de Manresa, 1714-1808. Tesis doctoral, Barcelona, Universitat Autònoma de Barcelona, 2004.

29. A diferencia de lo que se ha visto que sucedió con su hermano Valero, Juan obtuvo la titularidad del órgano tortosino por oposición, actuando Josep Escorihuela como juez examinador.

30. Hermano de José y de Valero, Juan Moreno y Polo (*La Hoz de la Vieja -Teruel-, 1711; †Tortosa -Tarragona-, 1776) se formó musicalmente como "infantico" en La Seo de Zaragoza, donde se registra su actividad como niño cantor, interpretando algunas de las composiciones "clásicas" catedralicias (los Magnificat de S. Aguilera de Heredia, el salmo "Quicumque" de Urbán de Vargas, etc.). Ahí mismo opositó en 1730 -con tan sólo 19 años- aunque sin éxito, a la organistía titular de la catedral metropolitana, cargo que obtuvo, entre diversos opositores, Joaquín Nebra. Un año más tarde, le encontramos ya opositando a la mencionada plaza de Tortosa. [Sobre Juan Moreno y Polo, véase: Preciado, Dionisio: Doce compositores aragoneses de tecla (siglo XVIII). Madrid, Editora Nacional, 1983, pp. 45-55; ID.: "Moreno y Polo. 2. Juan”, en Diccionario de música española e hispanoamericana. Vol. 7, Madrid, SGAE, 2000, p. 809; GEMBERo UstáRrOZ, María: "Moreno Polo. (2) Juan (Domingo) Moreno Polo", en The New Grove Dictionary of Music and Musicians. Vol. 17. New York, Oxford University Press, 2001, pp. 111-112]; EZQuerro Esteban, Antonio: "Nuevos datos para el estudio de los músicos Nebra en Aragón”, en Anuario Musical, 57 (2002), pp. 113-156. 


\section{Cantores $^{31}$}

Valero Sanz. Contralto (1680-1708). En el año 1680, el maestro de capilla Baltasar Sanz solicitó al cabildo un beneficio para su hermano Valero ${ }^{32}$ quien, después de ordenarse, fue admitido en la capilla como Contralto. Valero permaneció en Tortosa hasta su muerte, acaecida poco después de la de su propio hermano Baltasar, en 1708, año en que las actas reflejan que hay una plaza de "contralt vacant per mort de $\mathrm{M}^{\mathrm{o}}$ Valero Sanz" 33 .

Josep Boix ${ }^{34}$. Tenor (1696-1708). Del mismo modo que en el caso anterior, será el propio maestro Baltasar Sanz quien solicitará, en 1696, que sea admitido en la capilla, como cantor, José Boix ${ }^{35}$. Este músico ocuparía el cargo de Tenor en la misma, desde dicha fecha hasta su deceso, también en 1708.

Joan Garcia. Tenor (1708c). Este músico ayudó en su cargo al maestro Baltasar Sanz (previamente había sido su discípulo), durante los últimos años de su vida y se ocupó provisionalmente como interino, tras su deceso, de la capilla, hasta que se nombró al nuevo maestro ${ }^{36}$ Josep Escorihuela en marzo de 1708, de manera que, tras desempeñar dicho puesto durante tan sólo dos meses, Joan Garcia recibiría el siguiente pago por los servicios prestados:

[Margen:] "Substitut M.e de Capella" [contenido:] "[...] Deliberarunt que a $\mathrm{M}^{\mathrm{o}}$ Joan Garcia del temps ha regit lo magisteri de cant se ly donen los dos pans de cada dia conforme se donaven a Jaume Boix en la vacant antecedent" 37 .

Siendo Joan Garcia uno de los opositores en las polémicas oposiciones al magisterio tortosino que tuvieron lugar por entonces, fue el único aspirante considerado por el tribunal examinador "inhabil $\mathrm{M}^{\circ}$ Joan Garcia pbre per falta de pericia en la música" ${ }^{38}$. Tras dichos acontecimientos ocuparía, sin embar-

31. Aunque, a falta de un estudio más detenido de la documentación (que se pretende realizar en trabajos posteriores), se desconoce todavía en detalle el número exacto y nombre de todos los cantores que formaron parte de la capilla de música de la seo durante la primera mitad del setecientos, por el momento se dispone, sin embargo, de interesantes datos al respecto que conviene dar a conocer.

32. Véase: E: TO, Actas capitulares, 17.01.1680. Ambos hermanos eran naturales de Brea (Zaragoza).

33. Vid.: Ibid., 10.03.1708.

34. No hay que confundir a este José Boix con, al menos, otros dos músicos de mismo nombre y primer apellido de la época. Este José Boix murió en Tortosa en 1708, mientras que José Boix Nicolau murió en Valencia en 1712 y José Boix Cavaller seguiría vivo durante varios años más. Para más información sobre estos músicos véase: RIPOLLÉs PÉrez, Vicente: Músicos castellonenses. Castellón, Sociedad Castellonense de Cultura, 1936, pp. 161-162; Climent, José: "Boix Nicolau, José”, en Diccionario de la Música Española e Hispanoamericana. Vol. 2. Madrid, SGAE, 1999, pp. 550-551.

35. Carta encuadernada en: E: TO, Actas capitulares, 30.06.1696.

36. Joan Garcia era presbítero y beneficiado de la seo y, tras el traspaso de Baltasar Sanz (el 10 de enero de 1708), ese mismo día los capitulares decidieron aceptar su ofrecimiento de asumir el magisterio, como interino. [Véase: E: TO, Actas capitulares, 10.01.1708; GREGORI I CifRÉ, Josep Ma.: "Joan Crisòstom Ripollès (1678-1746) a les oposicions del magisteri de capella de la seu de Tortosa del 1708", en Butlletí arqueològic, V/14 (1992), pp. 137-147; para la cita concreta, p. 138].

37. E: TO, Actas capitulares, 27.03.1708.

38. Vid.: Ibid., 09.03.1708. 
go, en la capilla musical, el cargo de Tenor que había quedado vacante ese mismo año tras la muerte de Josep Boix. Este músico, siendo el único candidato en los exámenes, optó al puesto de Tenor en septiembre de 1708 mediante oposición y, en esa ocasión, sí que fue considerado por los examinadores apto para el puesto:

“[...] lo comensal Thomas Serrano M.e de orgue y $\mathrm{M}^{\mathrm{o}}$ Geroni Vermell pbre examinadors elegits per a les oposicions y examens de veu de thenor per la provissio de la comensalia vacant per mort del Comensal Joseph Boix en conformitat del edicte provehit lo dia 31 del passat, y feren relacio haven examinat a $\mathrm{M}^{\mathrm{o}}$ Joan Gassia pbre unich opositor, y habenlo trobat habil axi en veu de tenor com en cant"39.

Al igual que el cargo de maestro de capilla llevaba anexo una comensalía, al cargo de Tenor le correspondía la comensalía de San Agustín.

Otros cantores que en momentos puntuales ofrecieron sus servicios a la catedral, al menos en los primeros años de la centuria (aunque, al parecer, sin formar parte de la capilla musical propiamente dicha) serían, entre otros, Francisco Aragonés, Antoni Boix o Geroni Vermell ${ }^{40}$.

\section{Instrumentistas $^{41}$}

Tomás Fuentes. Chirimía y Bajón (1708c). Aunque se desconoce el período exacto en que este músico prestó sus servicios a la seo tortosina, se sabe que, al menos en 1708, Tomás Fuentes pertenecía a su capilla musical como músico de bajón y chirimía, por el siguiente documento:

“[...] a Thomas fuentes musich, de baixo y chirimia [...] se li done una reprehencio per les faltes fa en fer asistencia ab cuidado en la Igla per les funcions de combregars ocurexen, y se li advertexca lo cumpliment de sa obligacio, y que no habite fora los murs, sino dins ciutat pera que axi no storbe en falta a lo de sa obligacio $[\ldots]^{\prime 42}$

Al parecer, Tomás Fuentes no siempre cumplía del todo con sus obligaciones (según puede verse por el texto anterior) por lo que, al atribuirse en parte a que vivía fuera del recinto amurallado de la ciudad, se le aconseja que resida dentro del mismo para que le resulte más fácil cumplir con sus funciones en la capilla catedralicia.

39. Vid.: Ibid., 18.09.1708.

40. Vid.: Ibid., 18.09.1708. La situación "crítica" de la capilla era la causa de que, en ocasiones, se requiriese la participación en la misma de cantores y/o instrumentistas que no pertenecían propiamente a ella. Algunos de estos músicos estaban al servicio de alguna casa nobiliaria de la zona, como testimonian las Actas Capitulares de 7 de febrero de 1708 [E: TO], según las cuales los capitulares deliberaron que "se dónen als musichs, o, cantors de tiples que estan en casa del sr. Marquès de Bossianos, sis lliures a cada hu per lo molt han cantat y canten en la capella de la present iglesia" [véase: GREGORI, Josep Ma.: "La música a la Catedral de Tortosa a principis del segle XVIII: el memorial de l'organista Tomàs Serrano", en Recerca Musicològica, XIII (1998), pp. 63-76].

41. Sucede con los instrumentistas de esta capilla lo mismo que se ha visto sucedía con los cantores de la misma, esto es, se desconoce el número exacto y nombre de todos ellos, de manera que, por el momento, se ofrece una primera aproximación a los mismos, a la espera de un posterior estudio más pormenorizado de la documentación.

42. E: TO, Actas capitulares, 08.05.1708. 
José Amiguet. Violín (1731c). El maestro de capilla de Albarracín (Teruel), José Amiguet ${ }^{43}$, ocupó en la seo tortosina, al parecer, una plaza como violinista en 1731, cuando la capilla estaba regentada por Escorihuela. Jesús M. ${ }^{\text {a }}$ Muneta afirma que "parece ser que José Amiguet concurre a las oposiciones al magisterio de Capilla de la Catedral de Tortosa a finales de 1731, consiguiendo aquella plaza"44; sin embargo, todo apunta a que, si bien es cierto que Amiguet ocuparía un puesto en Tortosa a partir de esa fecha, no sería el del magisterio sino el de violinista, tal y como documenta Francesc Bonastre a partir de las actas capitulares de la Catedral de Lérida en las que, a raíz de unas oposiciones al magisterio de finales de abril de 1738 en dicho lugar, se afirma que uno de los candidatos era "Josep Amiguet, violinista de la Catedral de Tortosa"45.

Mariano Oller. Arpa (1707c). Al parecer, el arpa era un instrumento que, tradicionalmente (al menos durante parte del siglo XVII), no había formado parte de la capilla catedralicia tortosina, según puede verse por el siguiente documento:

[Carta de Baltasar Sanz al Cabildo, 1707:] “[...] Quando tuve la fortuna de poseer este Magisterio, allé en esta capilla la falta de no haver alguien que tuviesse la havilidad de Arpista, como la hay en las más Iglesias, siendo essa tan precissa para acompañar en la Quaresma, Semana Santa, Siestas y procesiones $[\ldots]^{\prime \prime 46}$.

Sin embargo, desde el momento en que el magisterio de la seo tortosina fue desempeñado por Baltasar Sanz, éste se encargó de que hubiese siempre algún músico preparado para tañer los acompañamientos requeridos por dicho instrumento, si bien no se sabe por el momento con certeza si llegó o no a existir en la capilla el cargo propiamente de "arpista", aunque al parecer no fue así hasta, al menos, 1707.

Sea como fuere, el propio Baltasar Sanz se preocupó, desde un principio, de que uno de los componentes de la capilla, el organista (acaso por considerarle el más hábil para realizar acompañamientos polifónicos), aprendiese a tañer este instrumento y, como ya se ha visto, parece que Tomás Lucas

43. Este músico natural de Tarrasa (Barcelona), se presentó a las oposiciones del magisterio vacante en Albarracín, por la muerte de Clemente Barrachina en 1728, en las cuales, los examinadores (Agustín Mesa, organista de la catedral de Albarracín y Luis Pastor, maestro de capilla de Teruel), dieron constancia al cabildo de que "Joseph Amiguet, natural de Tarrasa, era el más hábil e idóneo de los que habían conocido". Amiguet ocupó el magisterio de la catedral de Albarracín (donde actualmente se conservan algunas de sus composiciones) desde dicha fecha hasta que, a finales de 1731 entró a formar parte de la capilla de la seo tortosina. [Para más información sobre este músico, véase: MuNETA, Jesús M. a.: "Apuntes para la historia de la música en la catedral de Albarracín (Teruel): los maestros de capilla y organistas”, en Revista de Musicología, VI (1983), pp. 329-371; ID.: Catálogo del archivo de música de la catedral de Albarracín. Teruel, Instituto de Estudios Turolenses, 1984. ID.: "Amiguet, José", en Diccionario de la Música Española e Hispanoamericana. Vol. 1. Madrid, SGAE, 1999, p. 416].

44. Véase: MunETA, Jesús M. a. "Apuntes para la historia de la música en la catedral de Albarracín...”, op. cit., p. 340, así como “Amiguet, José”, en Diccionario de la Música Española..., op. cit., p. 416.

45. BonASTRE, Francesc: "Josep Carcoler (†1776): Notícia biogràfica i compositiva", en Recerca Musicològica, I (1981), pp. 113-150; cita concreta en p. 118.

46. BonASTRE, Francesc: "Nota biogràfica: Baltasar Sanz...”, op. cit., p. 141. El aragonés Baltasar Sanz, muy probablemente se había formado como infantico en El Pilar de Zaragoza y el arpa era un instrumento común en las capillas aragonesas, por lo que, a su llegada a Tortosa, este nuevo maestro se extrañó de que nadie tañese dicho instrumento, al menos como acompañamiento durante las festividades mencionadas. 
Serrano se ocupó de tañer el arpa hasta mediados de 1706, siendo Mariano Oller, al menos desde febrero de 1707 (y muy probablemente ya desde mediados de 1706), quien desempeñaría el cargo de arpista cuando las funciones de la catedral lo requerían, todavía bajo el magisterio de Baltasar Sanz:

[Carta de Baltasar Sanz al Cabildo, 1707:] "[...] Allándome sin tener quien supliesse esta falta [de arpista, por enfermedad de Tomás Lucas Serrano, el organista] procuré yngeniarme para suplirla, haziendo que Mariano Oller se aplicasse ha acompañar con dicho Instrumento, como ha proseguido asta el dia de oy [febrero 1707] [...]"47.

En la citada carta, el maestro Sanz solicitó un Beneficio para Mariano Oller, "en recompensa de esta gracia tañer el Arpa a todas las funciones que se ofrecieran en esta S.ta Iglesia y a la que la Capilla huviere menester fuera de ella", que no le fue concedido, muy probablemente a causa de las circunstancias económicas particularmente críticas que vivía la catedral y que, al parecer, eran consecuencia (a su vez) de los conflictos bélicos del momento, por cuanto dicha solicitud (de 22 de febrero de 1707) se denegó con el argumento de que "en vista de les males cobranses y contratemps en esta guerra, no·s troba àrbitre ni cabiment en admetrer á $\mathrm{M}^{\mathrm{o}}$ Mariano Oller clergue"48.

47. Bonastre, Francesc: "Nota biogràfica: Baltasar Sanz"..., op. cit., p. 141.

48. BonASTRE, Francesc: "Nota biogràfica: Baltasar Sanz"..., op. cit., p. 141. Se desconoce por el momento si Mariano Oller siguió ocupándose de tañer el arpa en la capilla tras dicha fecha (febrero de 1707), a pesar de que se le denegase el referido beneficio. 